\title{
Burnout Among Student-Athlete Services Professionals
}

\author{
Lisa Rubin, Ph.D. \\ Kansas State University \\ Maria Moreno-Pardo \\ AthLife, Inc.
}

Abstract: Literature on job burnout in athletics is limited to coaches, trainers, athletes, and administrators. Among student-services professionals, studies have focused on those in student support services, student affairs and mid-level administration. The purpose of this study was to explore factors why student-athlete services professionals burn out and consider leaving the profession. Themes from the literature on burnout include work overload, work environment/evaluation/supervision, social support, and values/motivation/expectations. The researchers sought volunteers from the N4A membership willing to be interviewed about burnout in the student-athletes services profession. Interviews were conducted in Fall 2016 with 38 professionals in the field including directors, assistant/associate directors, advisors, learning specialists, and student-athlete development professionals (with varying levels of experience in the field), which will inform athletic advisors and athletic administrators of the factors which lead to burnout and high turnover. The goal is to prevent burnout among talented student-athletes services professionals and their leaving the profession.

\section{Keywords: Burnout, Athletic Advising, Student-Athlete Services}

Burnout is "a state of physical, emotional, and mental exhaustion caused by long-term involvement in situations that are emotionally demanding. The emotional demands are most often caused by a combination of very high expectations and chronic situational stresses" (Pines \& Aronson, 1988, p. 9). Leiter and Maslach (2003) added, "Burnout is defined as a psychological syndrome of exhaustion, cynicism, and inefficacy" (p. 93). Defined this way, burnout serves as the conceptual framework for this research. Positions in the human services "are performed by...professionals who share three basic characteristics: (1) They perform emotionally taxing work; (2) they share certain personality characteristics that made them choose human service as a career; and (3) they share a 'client-centered' orientation. These three characteristics are the classic antecedents of burnout” (Pines \& Aronson, 1988, pp. 83-84).

Those who serve others often neglect their own emotional stress, focusing instead on who they serve (Pines \& Aronson, 1988). Professionals serving students at higher education institutions focus more on student development than their own personal development. Student-athlete services professionals include academic counselors, tutor coordinators, life skills program coordinators, and learning specialists among other titles and roles. These professionals serve a unique student population and have "one of the most challenging jobs in higher education" (Meyer, 2005, p. 15). 
Most positions that either support college students or that are housed in the athletic department are demanding in terms of time and expectations, and student-athlete support is no exception.

There is significant turnover in these positions. Literature on burnout in athletics has encompassed coaching (e.g., Kelley \& Gill, 1993), athletic staff members (e.g., McCarthy, 2015), and athletic trainers (e.g., Clapper \& Harris, 2008). A metaanalysis of "sport-burnout" literature focused primarily on student-athletes and coaches as well as a handful of administrators (Goodger, Gorely, Lavallee, \& Harwood, 2007). Goodger et al. (2007) called for "more qualitative research to further understanding of the individual experiences of burnout" (p. 147). Burnout research among student services professionals has examined student affairs educators (e.g., Guthrie, Woods, Cusker, \& Gregory, 2005), student support services personnel (e.g., Brewer \& Clippard, 2002), and midlevel leaders (e.g., Rosser, 2004). However, no studies have specifically explored burnout among student services professionals who specifically work with student-athletes. Rubin (2017) surveyed the membership of the National Association of Academic and Student-Athlete Development Professionals (N4A) and found that 91\% of respondents observed others experiencing burnout, and $60 \%$ considered leaving the profession of student-athlete services themselves. The purpose of this study was to explore factors that lead to student-athlete services professionals burn out and why they consider leaving the profession.

\section{Literature Review \& Theoretical Framework}

Since no research exists on burnout among student-athlete services professionals, the review of literature focused on job burnout, burnout in student affairs positions, and burnout in other athletic roles. Several themes emerged from the literature review: work overload, work environment/evaluation/supervision, social support, and values/motivation/expectations. These themes are analyzed individually. Burnout also serves as the theoretical framework for this study based on these four themes.

\section{Work Overload}

According to Leiter and Maslach (2003), the "most commonly discussed area of worklife is overload; job demands exceeding human limits. People have to do too much in too little time with too few resources" (p. 95). Professionals in college athletics tend to work long hours. Limited resources could indicate staff shortages. Due to limited resources, "there is a tendency to assign large numbers of clients to each staff member" which leads to work overload (Pines \& Aronson, 1988, p. 189). Besides having duties during typical work hours, these professionals work around student-athletes' schedules to provide services on evenings and weekends. Athletic department staff also attend athletic competitions whether for work duties or to support their students, and these events are not always during the workday. As Alden (in McCarthy, 2015, p. 5) noted, "People in intercollegiate athletics tend to stay connected. There's this $24 / 7$ mentality that has emerged and they feel that they don't have permission to disconnect." Guthrie et al. (2005) interviewed 11 student affairs educators from 11 four-year institutions, both public and private, to explore their personal and professional balance. They found that student affairs professionals also face "the 24/7 nature of the work" (Guthrie et al., 2005, p. 125). Student-athlete services staff have dual roles in both student affairs and athletics. This commitment and extension of time is a concern, as Pines and Aronson (1988) determined in their analysis of causes of and cures for burnout: "Some of the 
most difficult jobs are those in which professionals cannot distance themselves after working hours" (p. 91).

In their review of job burnout studies, Maslach, Schaufeli, and Leiter (2001) explained, "The notion here is that such dedicated people end up doing too much in support of their ideals, thus leading to exhaustion and eventual cynicism" related to their sacrifice (p. 405). Those who experience burnout are often the most enthusiastic for the work. Pines and Aronson (1988) offered, "Committed workers tend to burn out because they take on too much for too long and too intensely" (p. 152). Thus, professionals need to seek personal and professional balance, although this is often not found within this profession. One's level of autonomy and the work environment may have an impact on the journey for balance.

\section{Work Environment, Evaluation, and Supervision}

The work environment can influence professionals' job experience and potential burnout (Pines \& Aronson, 1988). Pines and Aronson (1988) explained, "Good work relations have a positive effect on both job satisfaction and people's general sense of well-being. On the other hand, a poor relationship with one's boss, subordinates, and colleagues is a major source of stress" (p. 38). In bureaucratic organizations, Pines and Aronson (1988) found that people struggle with "lack of personal control," leading to "a loss of individuality" in the "gigantic machine" (p. 106). To combat burnout, they suggested "a trusting and caring environment" (Pines \& Aronson, 1988, p. 171). Maslach et al. (2001) contended, "People thrive in a community and function best when they share praise, comfort, happiness, and humor with people they like and respect" (p. 415). The amount of autonomy and empowerment one has is related to the office culture and influences potential burnout. People are more satisfied when they have decision-making power and can take responsibility for their work (Leiter \& Maslach, 2003). Maslach et al. (2001) concurred, "Burnout is higher for people who have little participation in decision-making" (p. 407). How employees are evaluated and supervised are also factors of job burnout.

Professionals need clear criteria for evaluation of their work performance, which often comes from supervisors (Rosser, 2004; Thomas, Kolhi, \& Choi, 2014). Supervisors provide direction, support, feedback, and guidance for employees (Pines \& Aronson, 1988). These components of a job lead to the potential for success. When supervision is poor or lacking, or evaluation standards are unclear, job satisfaction is in jeopardy (Maslach et al., 2001; McCarthy, 2015, Thomas et al., 2014). Pines and Aronson (1988) emphasized, "As long as their involvement, commitment, and hard work are rewarded by continuous success, such high achievers can continue receiving a sense of meaning from their work indefinitely. They burn out when for some reason it is impossible to succeed" (p. 9). People want their efforts to be appreciated (Pines \& Aronson, 1988).

Rubin's (2017) survey of student-athlete services professionals found, "Evaluation of athletic advisors and other student-athlete services professionals remains a major area of concern. Anecdotal evidence suggests that athletic advisors may not know or understand the criteria on which they are evaluated" (p. 45). For professionals to be unsure of what is expected of them at work and how they will be evaluated is a serious issue, and could lead to burnout. A supportive 
environment, which may include an encouraging supervisor and helpful colleagues, may prevent these issues from occurring.

\section{Social Support}

Social support is a vital component to job satisfaction. Maslach et al. (2001) explained succinctly, "A lack of social support is linked to burnout" (p. 407). Brewer and Clippard (2002) measured burnout and job satisfaction among a national sample of student support services personnel via the Job Satisfaction Scale and the Maslach Burnout Inventory. They reported that a supportive environment was “one in which coworkers were helpful and looked out for each other's needs" (Brewer \& Clippard, 2002, p. 174). When employees determined a work environment to be hostile, they were more likely to leave the job (Brewer \& Clippard, 2002; Goodger et al., 2007). Employees sought "good peer bonding" which lowered their emotional exhaustion scores (Brewer \& Clippard, 2002, p. 174). Just as employees seek supervisory approval, peer recognition is equally important (Cross, Rebele, \& Grant, 2016; Maslach et al. 2001). Rosser (2004) investigated professional and institutional worklife issues that impact midlevel leaders in higher education. Her participants suggested that positive mentoring relationships are beneficial to their success on the job (Rosser, 2004). Relationships with coworkers and level of social support are also connected to burnout. Rosser (2004) also found that midlevel leaders in higher education "enjoy building positive relationships with colleagues within and between work units" and "have a strong sense of teamwork and communication" (p. 333).

Leiter and Maslach (2003) emphasized, “Social support reaffirms a person's membership in a group with a shared sense of values" (p. 98). In student-athlete services, professionals are often part of or connected to the athletic department, which itself is very insular. A sense of belonging is part of Maslow's (1943) Hierarchy of Needs pyramid (physiological, safety, love/belonging/esteem, self-actualization, in ascending order respectively), and is important in preventing burnout (Maslow, 1943). Pines and Aronson (1988) warned, "Workers tend to get so caught up in the daily routine of work that they neglect each other. They do not often enough or caringly enough compliment, support, and acknowledge each other's efforts" (p. 171). Kelley and Gill (1993) suggested that athletic educators also seek out social support in their work environment when stressed. The root of professionals' pursuit of a career is in their values, motivation, and expectations for work.

\section{Values, Motivation, and Expectations}

Professionals set expectations for themselves in their role and for their workplace. They also come to work daily with individual motivation, whether intrinsic or extrinsic, and a set of personal and professional values. Employees seek work in congruence with their own values (Leiter \& Maslach, 2003). According to Pines and Aronson (1988), "Burnout tends to afflict people who enter their professions highly motivated and idealistic, expecting their work to give their lives a sense of meaning" (p. 10). Guthrie et al. (2005) summarized these factors for student affairs professionals:

There are internal and external factors that affect one's ability to balance. They may serve as challenges or supports. Among these are (a) fit (or lack thereof) with the position and 
the institution, (b) supervisor's style and expectations, (c) amount of control one has in one's position, (d) culture of the student affairs division and institution, (e) meaning and satisfaction derived from one's work, (f) supportiveness of spouse or partner, and (g) individual's drive and level of optimism. (p. 125)

Student services professionals have an added pressure when aiming to attain personal and professional balance. Not only do professionals need to achieve balance, but must model it for students. Guthrie et al. (2005) noted, "As a profession, student affairs practitioners have the responsibility to role model for our students and staff a balanced and healthy approach to our personal and professional lives" (p. 125). The student affairs educators who participated in their study suggested the balance is a "developmental journey" that is "nuanced and extremely individualistic" (pp. 119, 124). The subjects provided strategies to improve personal and professional balance: "delegation, multitasking, judicious use of time, and setting boundaries...the critical nature of learning to say no" (Guthrie et al., 2005, p. 120). Not all professionals have the authority to delegate or feel comfortable saying no to others.

Based on the review of the literature, this study seeks to answer the follow questions: What factors and/or experiences lead student-athlete services professionals to burn out and consider leaving the profession? What are the profile characteristics of student-athlete services professionals who burn out and consider leaving the profession?

\section{Methodology}

The researchers are former student-athlete services professionals with over a decade each of membership in the field's professional organization, National Association of Academic and Student-Athlete Development Professionals (N4A; formerly National Association of Academic Advisors for Athletics). N4A, which has approximately 1,800 members, provides professional development for student-athlete services professionals (K. Newman, personal communication, November 1, 2017). Over this time, the authors of this study have observed burnout in the profession and have spoken with professionals considering leaving the profession. This led to the development of this research project. Costley, Elliott, and Gibbs (2010) discussed approaches for insider-researchers, noting the benefits on an informed perspective and depth of insider knowledge. They noted that insider-researchers' caring is "a moral obligation" (Costley et al., 2010, p. 57). Further, Costley et al. (2010) explained, "Caring requires a form of existential trust that transcends social roles configured through the power of others where those who trust you offer up their vulnerability, to reveal themselves" (p. 57). The researchers used convenience sampling to identify potential subjects to interview about their experiences leading to job burnout and their consideration of leaving the profession (Etikan, Musa, \& Alkassim, 2016). After obtaining permission from the N4A Board of Directors, an e-mail was sent to the organization's listserv requesting those interested in participating to contact us for more information and an informed consent form to review.

Those who were interested in participating reviewed and signed the informed consent and returned it via e-mail in a filtered inbox folder. Those who returned the signed consent form received access to a scheduling tool to select an interview time from October 2016 through January 2017, which included evenings and weekends, considering these are full-time working 
professionals. The researchers developed a set of interview questions (see Appendix A) that were asked in order for each participant. Interviews were conducted with 38 student-athlete services professionals $(n=38)$ in this time frame. Interviews were conducted using Zoom and Google Hangouts depending on which researcher led the interview. The researchers concluded each interview with a debriefing statement reviewing the study's purpose, information about confidentiality, and contact information for the IRB for any questions.

Both researchers sought to be present for all interviews, but sometimes only one was able to interview during the time slot. The recordings were "audio only" and stored on a password protected Google Drive account created specifically for this study. All e-mail correspondence with subjects utilized a study-specific e-mail address from this account once subjects agreed to participate. The recordings were submitted to Scribie, a service that converted all of the audio files into interview transcripts. The researchers each reviewed the transcripts to analyze the data, coding individually to ensure inter-coder reliability (Mouter \& Noordegraaf, 2012). After each researcher generated an initial set of codes and organized interview quotes by these codes, the team met to discuss patterns, overlap, and the language of both selected quotes and corresponding codes to further code the data, which required some reorganizing data from each author's separate master lists (Auerbach \& Silverstein, 2003). Reviewing the new combined codes, the researchers looked for emerging themes. Auerbach and Silverstein (2003) defined a theme as "an implicit topic that organizes a group of repeating ideas" (p. 42). Quotes from the participants best represented the themes that emerged, which were reduced in number from the initial coding process. Each participant was assigned a pseudonym (see Appendix B) to ensure anonymity in the study. From the interview data, participant information such as title/roles in position, student caseload numbers, and average number of hours worked per week was collected by the researchers.

\section{Positionality Statement}

Based on our previous experiences in this profession and involvement in the professional organization, we recognize our status as insider-researchers. This may have established trust with our participants prior to interviews, as we are familiar with the field and the vernacular used by its professionals. Costley et al. (2010) cautioned that as insider-researchers, it is an "epistemological impossibility" for us to be objective (p. 33). We hope by declaring our membership in the organization that provides professional development for this field, that we share our knowledge, experiences, and potential bias as it relates to this study.

\section{Results \& Discussion}

First, the profile characteristics of the participants are reviewed. Appendix B is a chart that includes the profile characteristics of the participants including titles/roles, caseloads, average number of hours worked per week, number of years in the profession, and number of institutions where participants worked thus far in their careers with pseudonyms. Then, themes from the interviews are shared. Analysis of the interview transcripts revealed seven themes represented by participant quotes from the interviews. Each of these quotes encompasses a variety of areas mentioned by the participants as analyzed through the burnout framework. 


\section{Profile Characteristics of the Participants}

Appendix B shows the wide range of titles and roles the study's participants represented. Participants included 22 professionals that directly work with student-athletes on a daily basis as academic, student-athlete development, or learning/tutoring professionals. The other 16 participants are in leadership positions within their units. From the interviews, we learned that student-athlete service professionals wear many hats outside of their titles and position descriptions. Several serve on campus committees, many are considered the "technology person" in the office and help colleagues with computer issues, and a number oversee student workers, study hall monitors, class checkers, and other part-time staff. Student-athlete services professionals in this study serve as liaisons to campus departments, organize mentoring programs, manage textbooks, advise the Student-Athlete Advisory Committee, fundraise for women's sports, and direct certification among other compliance activities.

Appendix B also has the approximate student caseloads assigned to the student-athlete services professionals in the study. The word approximate is used because student numbers are always changing, according to the participants. The responses indicate a wide variety in numbers, which could be for several reasons, such as supervisor approach, number of staff members, size of budget/resources available, number of athletic teams, and/or others. Respondents without individual caseloads indicated that they only supervised tutors or quantified their work with students by number of hours helping students rather than specific counts.

The chart in Appendix B reveals different hour ranges worked on average by the participants. Four participants suggested that their hours vary from 40 to 65 in any given week depending on if there are events, registration, or other duties that require more time. The two respondents with 70-80 hours are in leadership roles overseeing their units. Participant data indicates that the student-athlete services professionals who voluntarily participated in this study on burnout in the profession come from quite a varied number of years of experience. The average number of years worked in the profession among the participants is 9.9 years. Sarah felt that those new to the field were set-up for early career burnout. She expressed, "You know, I was just starting out, and it was unbearable the amount of work that they kind of piled on as your way to make it into the industry, and I think that's kind of the norm." With the same concerns, Marla observed, "You meet somebody and then two years later they're gone and you're like, 'What happened to this person?' They just kinda disappeared. They're not in the field anymore."

This study's participants worked at different numbers of institutions in the profession. About $42 \%$ of participants, the largest number, have worked at two institutions. However, over $47 \%$ have worked at three or more institutions, which is a significant number of places. Christina offered,

Obviously, I've been at four schools and in the same position, so a lot of times I kept thinking, 'Oh, it's gonna be better.' Or, 'It's a better location,' or what have you. And then what I realized at [last institution] is it doesn't matter where you are. It's not gonna be better. [chuckle] You're in an impossible position, asked to do impossible things without having the tools you need to do them. So I left the profession two weeks ago. 
Based on the information in Appendix B, the participants represent different lengths of their careers at different employers, so there is not a number of years or number of institution worked in the field that clearly represents when or how burnout may occur among student-athlete services professionals. The authors also looked at the athletic classification of the institutions where the participants worked. Thirteen came from Power 5 conferences, 12 from Football Bowl Subdivision (FBS) mid-major/Group of 5 institutions, eight from Football Championship Subdivision (FCS) institutions, and five from Division I-No Football institutions. None of the participants were from Division II or III, National Association of Intercollegiate Athletics (NAIA), or National Junior College Athletic Association (NJCAA) institutions.

\section{Positive Responses}

Many of the participants discussed positive experiences in the roles of student-athlete services professionals. These included special moments with students (e.g., graduation), seeing students' progress, and hearing from former students who were appreciative of their work. Respondents also discussed collaborative work environments with colleagues, loyalty to supervisors, and the rewards of seeing their students succeed. There are many strong quotes from participants about positives in the profession, so the burnout symptoms and discussion are not the only experiences faced by those in the field. There were, however, five emergent themes from the literature related to burnout or the consideration of leaving the profession.

\section{"I Don't See a Career Path"}

This theme represents participants' concerns about their future in the field, limited upward mobility, the lack of challenge and advancement, and the lack of confidence in transferable skills to another field. Emma's quote includes the theme: "I guess 'cause it's in my current situation I just don't feel very challenged. I don't feel like my talents are $100 \%$ used well in just being an advisor. So I just... I don't see a career path." Several participants echoed Emma when discussing lack of challenge and boredom. Pines and Aronson (1988) noted that monotony could cause people to become disillusioned with their work. If the nature of the work does not meet expectations, employees may experience burnout (Maslach et al., 2001).

Some participants discussed the difficulty of moving around the country to advance in the profession. Allison shared,

There's not really a lot of places to move up. And so you get to a point and then what's the next step? You've got to move. And you've got to move a lot of times, like across country, and so that gets exhausting too. So the idea of relocating, and restarting a life, just personally, is exhausting, and it gets to the point where I'm like, "I don't want to recreate my life again."

To achieve personal and professional balance and avoid burnout, Guthrie et al. (2005) suggested setting boundaries. For student-athlete services professionals, this is a difficult decision: choosing whether to move around the country for more opportunities or to stay in one location while seeking advancement in the career. In seeking stability for that balance, Chloe offered, "It was a stable job. Stable income. That's the primary reason why most of us stay in our jobs." Several participants 
felt it was easier to just stay in the position than looking for something else or changing professions. However, Allison cautioned, "It's burning you out, but it's your comfort zone. So it's a catch-22." Leiter and Maslach (2003) cautioned that Allison's situation makes it difficult for her to be fully committed to her profession.

Alternatively, some professionals are not interested in the next level in the profession. Julie explained, "Moving up to a more administrative role where all I'm really doing is, not all, but a big role is supervising people, that isn't appealing to me." Others felt trapped in their roles, where they could not develop skills. Alexa lamented about her supervisor:

Her management style was very much, 'you stick to the box that I've put you in. That's what I want you to do. That's what I need you to do, and that's what you're going to do, and it doesn't really matter what you need to be fulfilled as a professional. This is what I want you to do. This is what I envision for you and then that's it.'

The relationship with supervisors plays a key role here - without supervisor support, burnout can occur (Maslach et al., 2001). Because student-athlete services professionals are specialized, they did not feel like there could be an easy transition to another type of job. Chloe commented, "Because I had been in athletics for eight years, and I wasn't sure if my skills would be transferable anywhere." Amber labeled this the idea of being "pigeonholed" in her position, and Emma said it was "feeling stuck" and like people are "spinning their wheels."Sometimes, the symptoms of burnout lead to mental and physical health concerns.

\section{“It's Caused Me, Definitely, Some Health Issues"}

This theme represents participants' discussion about health issues, physical exhaustion, emotional stress, depression, and anxiety. Karina revealed, "I actually collapsed, probably about two to three months ago. [chuckle] And when they ran tests and everything, everything came back clear and everyone attributed it just the stress...I think majority of that stress was coming from work and some of the challenges that I experienced there." Sarah was diagnosed with chronic fatigue syndrome. Linda lamented, "I felt myself becoming unhealthy, and not knowing who I was anymore. Losing myself in my job. Even some depression at some times. I had to take medicine for depression and anxiety, at one point, because of my job." Unfortunately, she was not the only participant who experienced depression and anxiety because of her work. Brian even experienced regular panic attacks.

Victoria explained, "I think it's just kind of overall tiredness and just kind of lack of wanting to, maybe, get up to come to work the next morning... I think just overall lack of enthusiasm sometimes." Several participants, including Julie and Seth, mentioned a lack of sleep or inability to sleep because of the job. Both Carla and Nicole mentioned back pain and nerve damage, and Nicole even had to have back surgery. All of these health issues are related to work overload, a factor affecting job burnout. Participants also had various other health issues. Steve shared, "I was only at [previous institution] for six months, well, working there for six months, and I lost nearly 20 pounds, when I was at [previous institution], due to the stress, and pressure, and nature of having to deal with just one team, football which had a lot going on from my time there." Conversely, Carmen offered, "Weight gain, 'cause I don't eat properly and then eat in my office, and I'm eating 
whatever's on campus which is not always the best options." Though these are opposite issues, they are related to work environment.

Other health issues are very serious. Tracy was surprised to learn she developed symptoms of a disease with no cure:

I found out when I first got here and I was working 60 hours a week. Then later, because I was constantly exhausted, physically tired...Went to the doctor, found that I had onset of diabetes. So it was also processing that I now had a disease that I'd never had before, and coping with that and trying to realize the toll it takes on my body.

Alexa felt that the combination of health issues and work environment led to more problems. She explained,

When I was pregnant, it caused me to have to go on bed rest. Having a newborn is obviously exhausting in its own right. But add on a 60-hour work week with no compassion from your supervisor and...There were some days where I physically couldn't drive to work because my hands were so weak, I was so tired and my eyes were blurry, so my husband would have to drive me to work.

These health concerns are major. Angela told a harrowing tale:

When I was pregnant with my second child, I was told I did not get the promotion to be the director because I was pregnant, and they did not believe that I could handle stress because I was with child. So I decided that I would show them and work 'round the clock and ended up on bed rest and proved them I didn't have the ability to have the job because I couldn't actually come to work any longer. And then that also ended up that they expected me to work all through my maternity leave as well. I was at work a week after I gave birth. So, I would say that it caused not only physical harm to me, but to my child as well because then I didn't actually produce enough milk, and I couldn't breastfeed any longer 'cause I was so stressed.

Related to Alexa's and Angela's stories, women face a conflict between roles at home and at work (Pines \& Aronson, 1988). The consideration of these difficult work environments is important, because "burnout is the result of a social-psychological interaction between a person and an environment" (Pines \& Aronson, 1988, p. 153). A positive work environment is extremely important in mitigating health concerns, as a hostile work environment may lead employees to leave (Brewer \& Clippard, 2002).

\section{"We're Talking All These Time Demands for Student-Athletes, but No One's Talking about Time Demands for Our Staff and for Ourselves"}

This theme represents participants' burnout, their experiences viewing others in the profession burn out, and mental exhaustion. Angela's quote included the theme: 
I think the time demand, honestly. We're talking all these time demands for studentathletes, but no one's talking about time demands for our staff and for ourselves. And I think that's a real concern. We have these high expectations of what we're gonna do for these students who we're bringing in, who are underprepared, and then we don't talk about how we're doing self-care?

Considering that the National Collegiate Athletic Association (NCAA) recently passed legislation easing time demands on Division I student-athletes, it is interesting that the professionals who serve them do not get the same concern (Hosick, 2017). The pressure on student-athlete services professionals is immense, especially when considering that coaches depend on team wins. A team's success might depend on its top players, and it is someone in student-athlete services that holds the responsibility for student-athletes' eligibility. Olivia said, "I think some of them just can't deal with the coaches, the demands of it. I actually met a young lady at a conference, and she was brand new and as we kept in touch, within a year, she was out." Regarding this pressure, Linda shared,

I came to the point where I didn't know if I could do it anymore. I sometimes would come home and start crying. Sometimes I would break down in the middle of the day, and I didn't even really know why. It would just be a sense of exhaustion, overwhelmed. Just pressure when you're working with high-profile teams and high-profile sports.

Reflecting on her colleague, Christina mentioned, "I saw a co-worker pass out in a meeting with the entire football staff and football team, and we had to call an ambulance because he just hadn't [eaten] or slept in two days. It was the first week of fall." Angela, Linda, and Christina all discussed work overload. Guthrie et al. (2005) described the components necessary to achieve personal and professional balance: "(a) self-knowledge, (b) intentionality, (c) commitment to self care, and (d) reflection" (p. 116). Previously, Angela asked why self-care is not discussed. All of the stress, pressure, and limited rewards pile up, causing professional to experience burnout (Pines \& Aronson, 1988). These issues could be attributed to the type of work environment these professionals experience every day.

Josh felt that the coaches and administrators he works with do not respect him or his abilities on the job. He articulated, "If I'm gonna continuously be underappreciated and devalued, that's a hard thing to get over. I don't think I'll ever be able to get over it." Peer and colleague approval may reduce the need for supervisor recognition or burnout. Due to the frustration of the work, several participants said something similar to Allison's words: "I, on a very regular basis, think, 'What in the world can I do with my life that's not this?'" Amber said that this was a mismatch between professionals and their values, motivation, and expectation of the position.

Carmen felt that the job's alignment with personal values is a critical factor: "I think for some people, this job can tug on your values and what you value as a person because people might ask things of you that are not in line with your core values. And so when your values are challenged, I've seen people who have left because their values have been challenged as well." When people are initially attracted to a job based on their values and their experience changes that, burnout is a possibility (Leiter \& Maslach, 2003). Burnout can also be a result of professionals' experiencing cognitive dissonance with expectations, which are usually high at the beginning. In 
a supportive environment where they feel their work has meaning, they can be successful, which creates a motivational loop.

Alexa, who mentioned her struggles with personal and professional balance previously, left the profession right before her interview. She emphasized, "I'm probably the type of person that can keep pushing through physical exhaustion, but the emotional and spiritual exhaustion by far, takes the cake. And probably for the last five years, I have been emotionally drained. And I've only been out of the profession for four days and I already feel 10 times better." Samantha is now a "veteran" in the profession, but had to get used to the exhaustion. She mentioned, "I remember when I first started, the first few years I could just barely sit through a staff meeting by the end of the semester. I was just so burned, just burned." Maslach et al. (2001) noted that burnout is more of a risk early in a professional's career. That is why several participants suggested that burnout in student-athlete services occurs both with early career professionals and "veterans."

\section{"We're Not Paid Some Exceptional Amount of Money in Academics That We're Expected to Work 24 Hours a Day"}

This quote from Angela synthesizes a wide variety of topics including compensation, working on nights and weekends, limited vacation, lack of support, and lack of a professional mentor. The majority of the interview subjects were disappointed in their salaries. Nicholas explained, "I really love my job, but I think it could potentially be hard to maintain for a number of years and specially, it's not the most lucrative job in the world." Greg added, "I think the lack of money in our realm, in a sense, is kind of disheartening." Allison had more to add, including some observations about gender. She described,

Well, the compensation for what is done is not... It doesn't equal. You're not wellcompensated for the pressure and stress, and it's really hard to watch, to be in an environment where others are compensated greatly, and you're just forgotten about at the bottom, and are exhausted. You feel, at times, like you're the beck-and-call girl.

Nicole summed it up: "The pay sucks and the hours are long!" In their research, Pines and Aronson (1988) did not find a direct link between pay and burnout, suggesting that people get into helping professions for other reasons besides money. However, they did find that people expect appropriate pay.

Issues that the participants continuously brought up were working long hours, taking work home, working on weekends, and not taking vacations. Greg commented, "I come in every Sunday but I don't consider that a weekend anymore. It's because we are open on Sundays." To someone in a salaried position, this might sound absurd. Student-athlete services professionals are not paid overtime for work over the 37.5 or 40 hours prescribed by the positions they have. Angela, whose powerful quote set the tone for this theme, had a lot more to say about this issue. She expressed,

And I'm saying, 'Why can't we work 40 hours? Why can't this be a job, where we have somebody who actually respects our time? Why have we created this monster that there is a belief that if somebody texts me at 1:00 AM, I have to respond to them?' 
Victoria said of her institution, "I think that the culture here is that the students feel like we're accessible at all hours." Amanda shared frustrations with the size of her caseload, which added to her work overload. Just like Guthrie et al. (2005) suggested creating boundaries and saying no, Christina did the same. She articulated,

As I got older I realized, if I don't set boundaries and say no, people are gonna take advantage of that. That's why I only worked 45 to 50 hours at [last institution], and they'd say, 'You need to come in at night to monitor study hall.' I'd say, 'No, I'm not doing that.'

Not every professional has the courage to say no, though.

The lack of courage may be related to the work environment, relationship with the supervisor, and interactions with colleagues among other factors. Amber's supervisor both micromanaged her but was never around unless they bumped into each other on campus. Jacob's office has six advisors, and he shared that "we just all happen to work in the same office together and we're all our own little islands." Alexa's supervisor expected her to know everything about the profession already. She offered that her supervisor "didn't believe that professional development was important. She didn't believe that N4A was valuable, so therefore we didn't spend the money to do any of it." John, who shared that he learns more from his colleagues than his supervisors, noted, "That's probably the hardest part of whereas I don't get the feedback, or sometimes some training directly from my supervisor." This lack of support may lead to burnout. We did ask participants how often the staff in their units meet. There was a smorgasbord of responses, from weekly to monthly to nothing formally scheduled. Often, regularly scheduled meetings were cancelled. There was a lack of consistency in communication as a staff amongst the professionals we interviewed.

A large number of participants responded to the question about taking vacations during the year in the same way - they do not take them. Tracy added, "Then when we say, 'Oh well, maybe summer, we'll get a break.' Summertime? Nope. 'Cause now we're bringing in summer bridge [programs], or we have summer class that students are taking and we need to pay attention to those students." Alden cautioned athletic administrators, "It's also critical to set the example for your staff by taking vacations and not answering the phone after a certain hour unless it's an emergency" (McCarthy, 2015, p. 5). Pines and Aronson (1988) agreed, advocating, "People should not wait for a crisis to take time off. They must limit the number of hours on a given job and regularly take time off on evenings, weekends, and vacations" (pp. 151-152). However, the likelihood of this advice being heeded in student-athlete services and in athletics in general is low.

\section{"All We Get is a 'Thank You' at the Banquet, If We're Even Invited"}

This theme represents the lack of appreciation that these participants feel in the profession, motivations for leaving the field, and frustration with the system. Jessica summarized, "We're extremely underappreciated, but yet the first ones to point to and blame if something happens." This makes it impossible for professionals to succeed (Pines \& Aronson, 1988). Erin, who set the tone for this theme, described, 
And then the coach that gets the $\$ 50,000$ bonus because his APR is amazing at no point looks back at his advisor or learning specialist or whomever and says, 'You know what, I would like to share this with you,' or, 'Can I take you out to dinner,' or, 'Can I get you a gift card,' or...We don't get anything like that. All we get is a 'thank you' at the banquet, if we're even invited.

Linda had a very similar sentiment. She shared,

Sometimes I wouldn't even be invited to a team banquet, or if a team won a championship, I didn't get a team ring when every other support staff got a team ring. Just little things like that. Some teams would get a big box of gear for their advisor, and I didn't get any. I know those are little things, but the little things add up to make you feel like you're doing the right thing, you're appreciated. That's just one thing, the lack of appreciation.

Linda also expressed how the lack of recognition could lead to burnout. She explained, "You're expected to do, do, do, give, give, give, and then it feels like you don't get a whole lot back, particularly from the coaches and sometimes even your administrators." Rosser (2004) discussed the importance of recognizing midlevel leaders for their work. When administrators don't recognize work successes and achievements, employees may experience unease at work (Pines \& Aronson, 1988).

Whether this lack of recognition occurs at one place or many, Christina cautioned that it did not matter. She discussed, "And the reason I took it to do something else is 'cause when I look back at the past 12 to 13 years, it's always just surviving, it's never thriving. And it's always putting out one fire after another. There's never any gratitude or thanks, it's just that's what you're expected to do." Burnout is linked to under-appreciation. Carla added, "It's frustration with the system, and feeling powerless to do really anything about it." Amber echoed Carla about her issues with the system, saying, "The sheer model, the money that's involved, the wins and losses, the prioritization of that over education, many reasons." This is directly related to burnout symptoms, "including physical depletion, feelings of helplessness and hopelessness, disillusionment, and the development of a negative self-concept and negative attitudes toward work, people involved in the work, and life itself" (Pines \& Aronson, 1988, p. 9).

Brian felt that his work environment based on this system was definitely part of the problem. He clarified, "A lot of the time we're set up for failure with this profession and there's really no way around it because of all the factors involved with everything outside of our department that affects us here." Victoria discussed the changing nature of the students: "It's just getting to where we're giving them more and more and they're becoming more entitled or just more that they expect that these are the things that we should provide to them and they don't really see it as this is an opportunity for them but more as a, 'We're a student-athlete, so you need to give this to us." Working with entitled students does not align with student-athlete services professionals' values. Southern Methodist University's women's basketball coach Rhonda Rompola retired in 2016 citing student-athlete entitlement as her reason for leaving her successful profession coaching student-athletes unexpectedly early (Associated Press, 2016). Sabrina felt that the students needed more "parenting" and "coddling" than in previous years on the job. Steve 
summarized, "I think the degree of the type of student that we are getting every year seems to be declining every year."

Amanda expressed frustration with the idea that the rest of campus does not understand what her job entails. Matt said his work environment is such that there is a stigma attached to someone who leaves work at 5:00 PM to go home. Sarah discussed the problem with achieving work/life balance in this role: "Just looking at the long-term development and growth, is it sustainable to, really, keep up an average of 50 hours a week and care for a family? At my previous institution, I was working no less than 60 on any given week, and it was extra unrealistic." All of this effort may just end up leading to burnout. Erin synthesized, "For most people, that's why we start to burn out is that...We know that this is a thankless job, but sometimes just... It would be nice for somebody to say 'Thank you,' and that doesn't often happen. If ever.' As Josh noted earlier, it is hard to recover from feeling devalued.

\section{Implications}

According to Pines and Aronson (1988),

The major strategies for dealing with burnout consist of: (1) becoming aware of the problem, (2) taking responsibility for doing something about it, (3) achieving some degree of cognitive clarity, and (4) developing new tools for coping, improving the range and quality of old tools. (p. 27)

What follows is a series of innovative strategies to prevent burnout through the participants' experiences and the burnout framework that emerged from the literature.

\section{Implications for Student Athlete Services Professionals}

Many student-athlete services professionals who reported feelings of burnout also carried a heavy workload with high caseloads and additional responsibilities such as oversight of the tutor program. Brewer and Clippard (2002) suggested high burnout and low job satisfaction are connected to work overload, role conflict, and ambiguity among other factors. It is recommended that student-athlete services professionals self-evaluate their caseload and roles and responsibilities within their unit and discuss with their supervisor when an issue of imbalance exists.It is important for student-athlete services professionals to have consistent and direct communication with their supervisor. Requesting monthly check-in meetings with their supervisor is recommended as a good method to report workload concerns, as well as role expectations. Also, it is critical for new staff members to discuss their philosophy and approach to working with student-athletes with their supervisor upon starting. When a new professional starts this conversation, it enables the supervisor to share expectations and establish criteria for annual evaluations.

Another area in which student-athlete services professionals attributed to burnout was the lack of professional growth. While there are limited opportunities to grow into assistant director or higher roles, it would be beneficial for student-athlete services professionals to clearly articulate their career path goals with their supervisors. This can be done during yearly evaluations or during informal check-in meetings. Additionally, volunteering to take on roles and responsibilities within 
their unit geared toward developing their professional skills (e.g., supervising staff or serving on committees) is recommended. For example, an advisor can offer to help with tutor training or supervision of interns. Not only will taking on new roles help individuals get new skills on their resume, it can also provide a change of pace from their current duties. Requesting change of teams for advising purposes when appropriate and possible is also a good way to prevent burnout by providing a change from working with the same coaches and students.

Student-athlete services professionals work long hours and often only take time off during extended weekends. It is advised that planning and taking yearly vacations longer than extended weekends would benefit student-athlete services professionals. During any time away from the office student-athlete services professionals should be proactive and "disconnect" from work by setting out-of-office email, having another staff member as their back-up for any emergency, and not check their work email or phone. These suggestions can go a long way to provide a break from the long weeks and stressful days often faced by student-athlete services professionals. Furthermore when taking a vacation is not possible, it would also be a good idea to take random days off during the academic year to help individuals step away and take a break to re-charge from the daily stressors of the job.

\section{Implications for Administrators of Student-Athlete Support Units}

Work environment, evaluation, and supervision. One major concern is that studentathlete services professionals may be unclear about how they are evaluated on the job. Cross et al. (2016) appropriately referred to sports for an analogy, "Consider professional basketball, hockey, and soccer teams. They don't just measure goals; they also track assists. Organizations should do the same, using tools such as network analysis, peer recognition programs, and valueadded performance metrics" (p. 79). From the very beginning of an employee's start in a studentathlete support unit, supervisors should establish clear evaluation criteria and provide regular feedback throughout the year. As Cross et al. (2016) suggested, establishing peer recognition can create a positive office culture where staff members pay attention to each other's hard work and creative contributions. Supervisors should find ways to incentivize staff, whether monetarily or through recognition programs/potential promotions. If salary increases or bonuses are not an option, title changes are a welcome idea. Unlike in other areas of athletics where entry level positions may start with the title of "Assistant Director," most student-athlete services professionals have a title related to "Coordinator," "Advisor," "Specialist," or "Counselor." It may take five or more years to achieve a title change. Supervisors can reward extraordinary work with a promotion in the form of a title change. This may seem unusual to promote someone without providing more money, but it could benefit the career trajectory of a professional through the title change and obvious confidence in that person's abilities.

Maslach et al. (2001) indicated that employees who do not have decision-making power often burn out. Staff should be empowered to make decisions that benefit the unit. Many acclaimed service models (e.g., Nordstrom, Ritz Carlton) empower staff to make decisions to please customers. It is important to enable student-athlete services professionals to make decisions for their students and the unit because it shows trust in their abilities. As Josh mentioned previously, he struggles with overcoming feeling devalued, like his work is not trustworthy. It is also important for supervisors to remove any stigma of leaving at 5:00 PM if a professional does not need to work at night. No professionals should feel compelled to "stick around" because of how they are 
perceived by coworkers or supervisors. As a unit, employees should set boundaries with students and coaches about how late they can call a staff member at home. Otherwise, there is clearly a lack of respect for professionals' time, unless they are willing to take calls at all hours.

Work overload. Athletic departments should encourage vacations during "down times" (e.g., after registration period, during winter break). To supervisors, McCarthy (2015) suggested, "It's also critical to set the example for your staff by taking vacations and not answering the phone after a certain hour unless it's an emergency" (p. 5). In athletics, staff are regularly working events outside of the normal work day, monitoring nightly study hall, or helping at athletic contents. In this case, they should be allowed to come in later in the morning the day they work late, or come in later the day following a long day/late night. Professionals who get more balance with time and more sleep will likely be more productive. Also, each professional should have a manageable student caseload. This may not be so easily achieved at a low resource institution or if the unit is short-staffed. However, most of these units have the goal to develop and graduate student-athletes. It is very difficult for a professional to develop relationships with students and provide individualized approaches for them if the caseload is too high. There are not enough hours in the day for support professionals to meet with high numbers of students, especially as registration time approaches.

Social support. Student-athlete services professionals would benefit from the establishment of a formal mentoring program. This could be within athletics (e.g., an academic advisor with the opportunity to be mentored by a marketing director) or with campus student affairs or other academic advising units. The key is to focus on professional development and ensure people are growing in a way that can add value to the institution and the student-athletes' experiences also. In addition to creating a mentor program on campus, departments should support professional development opportunities for their staff, such as paying for their N4A membership and costs to attend conferences, encouraging them to seek a mentor through N4A and participate in relevant Professional Development Institute (PDI) tracks, and providing time for staff to get involved in campus committees and professional development programming. These opportunities also allow student-athlete services professionals to expand their social capital on campus and nationally through networking. Mentors can help professionals set boundaries, manage unspoken supervisor expectations, prevent physical and emotional fatigue by recognizing symptoms early on, and maintaining social support networks (Rosser, 2004).

Another way to highlight social support is to have a staff appreciation event each semester and enable staff to bring significant others, family members, and friends. There are many recognition opportunities for student-athletes through the institution, conference, and sport governing body, but less so for the hardworking professionals that serve them. Mentoring opportunities and peer recognition make a major difference in burnout prevention (Cross et al., 2016; Rosser, 2004).

Values, motivation, and expectations. The unit should encourage staff to take time for themselves and their family, placing an emphasis on self-care. To avoid someone feeling a lack of challenge or that talents are not fully utilized, unit directors should consider reorganizing the office with "other duties as assigned" so people gain new skills and get the chance to do something that may align with personal interests. For example, if someone has served as a tutor coordinator and liaison to disability support services, perhaps they can swap those duties with a colleague who 
organizes community service activities for the student-athletes. Another idea is to reorganize sport assignments every few years. That might retain professionals who have friction with coaches or are tired of working with the same teams. If they continue working in the office with new studentathletes, they will still be around to see the students they started working with graduate.

Another important suggestion to ensure that office culture is one with positive values consistent with the profession is to make sure staff follow the N4A Code of Ethics. This document emphasizes professionals' responsibilities both to their students and their institutions (N4A, 2011). However, before someone is hired, the unit's team members and other athletic department staff should ensure that new hires are a good fit for the office culture and would not go against the unit's and department's values. It might be difficult to determine this during an interview, but with everyone seeking the best fit for the office, it is more likely to find someone who would thrive in the office environment and be less likely to burn out in the future.

\section{Limitations}

The interview questions (see Appendix A) might have created bias through the ordering of them. These questions may have hinted to participants that there is a connection between burnout and leaving the profession.

Results from 38 participants are not representative of the views and experiences of all student-athlete services professionals, so the information shared is not generalizable to the profession. Hopefully, though, this sample reflects some of the common concerns and views that these professionals have relative to their work experiences, potential burnout, and the consideration of leaving the profession. Also, unlike in Rubin's (2017) study, we did not ask the participants if they were former student-athletes. It is possible that this information may be an additional factor to how student-athlete services professionals manage their workload.

\section{Conclusion}

Nicholas declared, "I think anyone that you talk to that says they haven't considered the potential to get burned out, or the potential to switch careers, is probably lying...everyone that's in it has to be in it 'cause they love it, and if you don't it's a really hard profession to be in." He pinpointed a major concern for the profession: that everyone has thought about burnout and has considered leaving the profession. Because of this reality and the high turnover in the field, preventing burnout needs be at the forefront of athletic administrators' minds in college athletics. There are very talented individuals entering this field every year, and institutions can improve these different areas such as work environment and overload, to retain this talent. 


\section{References}

Associated Press. (2016, February 25). Coach says athlete entitlement a factor in her retirement. Sports Illustrated. Retrieved from https://www.si.com/womens-collegebasketball/2016/02/25/ap-bkw-smu-rompola

Auerbach, C., \& Silverstein, L. B. (2003). Qualitative data: An introduction to coding and analysis. New York, NY: NYU Press.

Brewer, E. W., \& Clippard, L. F. (2002). Burnout and job satisfaction among student support services personnel. Human Resource Development Quarterly, 13(2), 169-186.

Clapper, D.C., \& Harris, L.L. (2008). Reliability and validity of an instrument to describe burnout among collegiate athletic trainers. Journal of Athletic Training, 43(1), 62-69.

Costley, C., Elliott, G. C., \& Gibbs, P. (2010). Doing work based research: Approaches to enquiry for insider-researchers. London: SAGE Publications.

Cross, R., Rebele, R., \& Grant, A. (2016). Collaborative overload. Harvard Business Review, 94(1-2), 74-79.

Etikan, I., Musa, S. A., Alkassim, R. S. (2016). Comparison of convenience sampling and purposive sampling. American Journal of Theoretical and Applied Statistics, 5, 1-4.

Goodger, K., Gorely, T., Lavallee, D., \& Harwood, C. (2007). Burnout in sport: A systematic review. The Sport Psychologist, 21, 127-151.

Guthrie, V. L., Woods, E., Cusker, C., \& Gregory, M. (2005). A portrait of balance: Personal and professional balance among student affairs educators. The College Student Affairs Journal, 24(2), 110-127.

Hosick, M. B. (2017, January 20). DI student-athletes to have more time away from sports [Press 
release]. Retrieved from http://www.ncaa.org/about/resources/media-center/news/distudent-athletes-have-more-time-away-sports

Kelley, B. C., \& Gill, D. L. (1993). An examination of personal/situational variables, stress appraisal, and burnout in collegiate teacher-coaches. Research Quarterly for Exercise and Sport, 64, 94-102.

Leiter, M. P., \& Maslach, C. (2003). Areas of worklife: A structured approach to organizational predictors of job burnout. Research in Occupational Stress and Well Being, 3, 91-134.

Maslach, C., Schaufeli, W. B., \& Leiter, M. P. (2001). Job burnout. Annual Review of Psychology, 52, 397-422.

Maslow, A.H. (1943). A theory of human motivation. Psychological Review, 50(4), 370-396.

McCarthy, C. (2015). Prevent, address burnout among your athletics department staff members, coaches. College Athletics and the Law, 12(4), 1-5.

Meyer, S. K. (2005). NCAA academic reforms: Maintaining the balance between academics and athletics. Phi Kappa Phi Forum, 85(3), 15-18.

Mouter, N, \& Noordegraaf, D. V. (2012, October). Intercoder reliability for qualitative research: You win some, but do you lose some as well? Paper presented at the $12^{\text {th }}$ TRAIL Conference, Rotterdam, Netherlands.

National Association of Academic Advisors for Athletics (N4A). (2011). Code of ethics. Retrieved from http://grfx.cstv.com/photos/schools/nacda/sports/nfoura/auto_pdf/201112/misc_non_event/codeofethics.pdf

Pines, A., \& Aronson, E. (1988). Career burnout: Causes and cures. New York, NY: The Free Press.

Rosser, V. J. (2004). A national study on midlevel leaders in higher education: The unsung 
professionals in the academy. Higher Education, 48(3), 317-337.

Rubin, L. M. (2017). Who are athletic advisors? State of the profession. NACADA Journal, 37(1), 37-50. doi:10.12930/NACADA-15-046

Thomas, M., Kohli, V., \& Choi, J. (2014). Correlates of job burnout among human services workers: Implications for workforce retention. Journal of Sociology \& Social Welfare, 41(4), 69-90. 
Appendix A

Interview Questions

1) What roles do you have in your current position?

2) How many institutions have you worked at in the field?

3) How many years have you worked in the field?

4) What kind of support do you get from your supervisor?

5) On average, how many hours a week do you work?

6) How often do you take vacation during the academic year?

7) Do you take work home or go to work on the weekends?

8) How often does the staff in your unit meet?

9) How many student-athletes are in your caseload?

10) Do you seek advice from your coworkers?

a. [If yes] How often? For what types of concerns?

11) Do you have a professional mentor?

12) Has work caused you any physical exhaustion?

13) Has work caused you any emotional exhaustion?

14) Have you experienced burnout in your job?

15) Have you previously discussed feeling burned out with anyone?

a. [if yes] Who have you discussed your feelings of burnout with?

16) Have you considered leaving the student-athlete services profession?

a. [If yes] For what reasons have you considered leaving the profession?

17) What factors keep you motivated to stay in your current position?

18) What factors keep you motivated to stay in this profession?

19) Have you observed others experiencing burnout? What kinds of symptoms did they exhibit? 
Appendix B

Participant Profile Characteristics

\begin{tabular}{|c|c|c|c|c|c|}
\hline Pseudonym & $\begin{array}{l}\text { Years in } \\
\text { Profession }\end{array}$ & $\begin{array}{l}\text { Number of } \\
\text { Institutions } \\
\text { Participant } \\
\text { Has Worked }\end{array}$ & $\begin{array}{l}\text { Average \# of } \\
\text { Hours } \\
\text { Worked per } \\
\text { Week }\end{array}$ & *Position/Roles & $* *$ Caseload \\
\hline Nicholas & 7 & 5 & 50 & $\begin{array}{c}\text { Learning Specialist/Tutor } \\
\text { Coordinator }\end{array}$ & 21 \\
\hline Tiffany & 12 & 2 & $45-50$ & Director & 100 direct oversight \\
\hline Linda & 15 & 5 & 50 & Director & $\begin{array}{c}300 \text { total, } 90 \text { direct } \\
\text { oversight }\end{array}$ \\
\hline Greg & 5 & 2 & 60 & Advisor/Tutor Coordinator & $\begin{array}{c}22 \text { students, } 100 \\
\text { tutors }\end{array}$ \\
\hline Marla & 23 & 3 & 80 & Director & 75 direct, 380 total \\
\hline Carla & 24 & 5 & 45 & Drictor & 375 total, 115 direct \\
\hline Chloe & 8 & 4 & 40 & Advisor & 120 \\
\hline Brian & 9 & 1 & $50-60$ & $\begin{array}{l}\text { Assistant Director/Tutor } \\
\text { Coordinator }\end{array}$ & 45 \\
\hline Jessica & 10 & 4 & $40-65$ & Director & 350 total \\
\hline Josh & 3 & 2 & $40-60$ & Advisor & 175 \\
\hline Samantha & 8 & 2 & 40 & $\begin{array}{l}\text { Learning Specialist/Tutor } \\
\text { Coordinator } \\
\end{array}$ & 15 \\
\hline Allison & 5 & 2 & $45-60$ & Director & 315 total \\
\hline Mary & 3 & 2 & $55-60$ & Advisor & 105 \\
\hline Carmen & 8 & 3 & 60 & Director/Advisor & 403 total \\
\hline Kayla & 2 & 2 & $55-60$ & Advisor/Tutor Coordinator & 67 \\
\hline Steve & 14 & 5 & $40-45$ & Director/Advisor & 150 direct \\
\hline Kendra & 12 & 5 & 60 & Director & 35 \\
\hline Erin & 10 & 4 & $50-60$ & Advisor & 200 direct \\
\hline Sarah & 4 & 2 & 50 & $\begin{array}{c}\text { Student-Athlete Development } \\
\text { Coordinator }\end{array}$ & 105 \\
\hline Olivia & 8 & 5 & $40-50$ & Assistant Director/Advisor & 60 \\
\hline Angela & 15 & 3 & 60 & Director/Advisor & 125 \\
\hline Christina & 13 & 4 & $45-65$ & $\begin{array}{l}\text { Learning Specialist/Tutor } \\
\text { Coordinator }\end{array}$ & $\begin{array}{l}100 \text { as Learning } \\
\text { Specialist }\end{array}$ \\
\hline Julie & 11 & 3 & $50-60$ & $\begin{array}{l}\text { Assistant Director/Advisor/Tutor } \\
\text { Coordinator }\end{array}$ & 105 \\
\hline Alexa & 8 & 3 & $55-60$ & $\begin{array}{c}\text { Assistant Director/Tutor } \\
\text { Coordinator } \\
\end{array}$ & 10 tutorees \\
\hline John & 8 & 3 & $45-50$ & Advisor & 420 total, 190 direct \\
\hline Matt & 6 & 3 & $40-50$ & Advisor & 80 \\
\hline Tina & 25 & 5 & 60 & Director & 110 direct \\
\hline
\end{tabular}




\begin{tabular}{|c|c|c|c|c|c|}
\hline Pseudonym & $\begin{array}{c}\text { Years in } \\
\text { Profession }\end{array}$ & $\begin{array}{c}\text { Number of } \\
\text { Institutions } \\
\text { Participant } \\
\text { Has Worked }\end{array}$ & $\begin{array}{c}\text { Average \# of } \\
\text { Hours } \\
\text { Worked per } \\
\text { Week } \\
\end{array}$ & *Position/Roles & $* *$ Caseload \\
\hline Teresa & 4 & 1 & $50-60$ & Assistant Director & 215 \\
\hline Jacob & 10 & 2 & $45-50$ & Associate Director/Advisor & 71 \\
\hline Seth & 10 & 2 & 37.5 & $\begin{array}{c}\text { Associate Director/Learning } \\
\text { Specialist }\end{array}$ & 47 direct, 423 total \\
\hline Amanda & 12 & 2 & $50-55$ & $\begin{array}{c}\text { Advisor/Learning } \\
\text { Specialist/Tutor Coordinator }\end{array}$ & 200 (30 at-risk) \\
\hline Nicole & 17 & 1 & 65 & $\begin{array}{c}\text { Assistant Director/Learning } \\
\text { Specialist }\end{array}$ & 22 \\
\hline Sabrina & 10 & 2 & 55 & Director & 80 direct \\
\hline Tracy & 4 & 1 & 43 & Advisor & 95 \\
\hline Amber & 12 & 2 & 50 & $\begin{array}{c}\text { Associate Director/Learning } \\
\text { Specialist }\end{array}$ & $\begin{array}{c}\text { 20-25 hours a week } \\
\text { with students for } \\
\text { Learning support }\end{array}$ \\
\hline Karina & 6 & 2 & 70 & Director & 125 direct, 550 total \\
\hline Emma & 8 & 2 & $50-60$ & Advisor & 125 \\
\hline Victoria & 6 & 2 & $40-50$ & Advisor & 50 \\
\hline
\end{tabular}

*Participants reported various roles and responsibilities for purposes of this table the primary role/title(s) are listed

**For directors their caseload numbers reflect the number of student-athletes their unit supports if applicable their personal advising caseload is noted. 